\title{
ОСОБЕННОСТИ ПРАКТИЧЕСКОГО ПРИМЕНЕНИЯ УПРАВЛЕНИЯ ПО РЕЗУЛЬТАТАМ В ОБЩЕОБРАЗОВАТЕЛЬНЫХ УЧРЕЖДЕНИЯХ В УСЛОВИЯХ НОРМАТИВНО-ПОДУШЕВОГО ФИНАНСИРОВАНИЯ
}

\author{
(c) 2018 Иванова Валентина Николаевна \\ доктор экономических наук, профессор \\ Ректор
}

Московский государственный университет технологий и управления им. К.Г. Разумовского

(Первый казачий университет)

109004, г. Москва, ул. Земляной вал, д. 73

E-mail: oet2004@ya.ru

(c) 2018 Оздарбиев Рамзан Гусайнович

Начальник отдела мониторинга и анализа Управления оценки качества общего образования Федеральная служба по надзору в сфере образования и науки Российской Федерации

127994, г. Москва, ул. Садовая-Сухаревская, д. 16, К-51, ГСП-4

E-mail: oet2004@ya.ru

(c) 2018 Таточенко Ирина Михайловна

кандидат технических наук, доцент

Московский государственный университет технологий и управления им. К.Г. Разумовского

(Первый казачий университет)

109004, г. Москва, ул. Земляной вал, д. 73

E-mail: a.fem@yandex.ru

В статье рассматриваются вопросы повышения эффективности деятельности общеобразовательных учреждений в условиях нормативно-подушевого финансирования. Показано, что фактические объемы бюджетного финансирования являются достаточными для обеспечения зарплаты педагогов на уровне средней зарплаты по экономике. Однако несовершенство региональных процедур расчета душевого норматива финансирования, а также доведения выделяемых средств до средних общеобразовательных школ существенно снижают эффективность работы системы общего образования в субъектах Российской Федерации. Авторами предлагается методика распределения бюджетных средств, базирующаяся на принципе управления по результатам, при котором объем получаемых средств напрямую зависит от комплексной оценки эффективности проведения учебного процесса в школах региона. Также предложен метод упрощенного расчета душевого норматива финансирования, основанный на гарантированном обеспечении учителям зарплаты, соответствующей среднему уровню по экономике. Применение предлагаемой методики позволит существенно повысить эффективность труда педагогического персонала.

Ключевые слова: управление по результатам, эффективность труда персонала, нормативно-подушевое финансирование, заработная плата педагогических работников.

Достаточно общим мотивом исследований, посвященных проблемам отечественного образования - [1] и др.- стал тезис о недостаточности объемов его финансирования, в т.ч.- и средних общеобразовательных школ (СОШ). В современных условиях основным источником финансирования общеобразовательных организаций являются государственные бюджеты различных уровней. Так, в структуре располагаемых средств СОШ бюджеты субъектов РФ занимают долю около 78\%, местные (муници- пальные) бюджеты - немногим более $17 \%$, а федеральный бюджет - менее 10\%. При этом доля средств, самостоятельно зарабатываемых или привлекаемых СОШ, не превышает 3,5\% [2]. Не вызывает сомнений необходимость контроля корректности распределения направляемых в систему общего образования бюджетных средств, а также эффективности их использования. При этом следует иметь в виду, что представления об эффективности работы системы образования могут существенно варьироваться 
на различных уровнях. Так, в работе [3] выделяются следующие субъекты, участвующие в образовательном процессе и заинтересованные в его результатах: а) государство, б) регион, в) предприятие (фирма), г) семья (учащийся). Основные мотивационные побуждения субъектов при этом следующие:

- государство: активизация процессов социализации за счет формирования в процессе обучения поколения, приспособленного к самостоятельной жизни, экономически активного и социально ответственного, обладающего минимальными профессиональными навыками;

- регион: обеспечение занятости и социальной защиты наиболее неустойчивой категории населения (молодежи в возрасте 13-18 лет) за счет согласования потребностей рынка труда и возможностей рынка образовательных услуг на региональном уровне;

- предприятие (фирма): получение в лице выпускника школы потенциального работника - грамотного, ответственного, обладающего адекватной самооценкой и способностью к саморазвитию в перспективе дальнейшего профессионального роста;

- семья (учащийся): перспектива получения престижной профессии, обеспечивающей материальный достаток и положение в обществе, и при этом соответствующей личностным (физическим, психологическим, ментальным и пр.) характеристикам учащегося.

По нашему мнению, к приведенному перечню необходимо добавить СОШ как непосредственного организатора учебного процесса. Приоритетами для данного субъекта будет выступать обеспечение своим работникам достойной заработной платы и успешной профессиональной реализации. Доведение зарплаты педагогических работников общего образования до уровня средней по экономике - одна из ключевых задач Президентских инаугурационных указов 2012 г. [4], [5]. При этом размер заработной платы данной категории персонала должен тесно коррелировать с эффективностью труда, т.е. с достигнутыми результатами учебного процесса, оцениваемыми на основе системы объективных показателей. Возможности для этого предоставляет новая система оплаты труда (НСОТ), базирующаяся на известном принципе управления по результатам [6].

В условиях перехода к рыночным отношениям представляется целесообразным подход, при котором каждый из перечисленных субъектов принимает участие в финансировании той составляющей образовательного процесса, в которой он наиболее заинтересован. Как результат, на основе принципов частно-государственного партнерства соблюдается баланс интересов государства, работодателя, домохозяйства, а также образовательного учреждения. В рассматриваемой ситуации государство выступает регулятором долевого участия субъектов в финансировании [3]. При этом следует иметь в виду, что в настоящее время финансирование системы общего образования осуществляется на основе нормативно-подушевого подхода, не всегда обеспечивающего адекватную оценку реальных затрат СОШ на организацию качественного и современного учебного процесса.

Существующая практика определения душевых нормативов финансирования СОШ достаточно подробно и притом весьма критически рассматривается в исследованиях НИУ ВШЭ [7], [8]. Следует заметить, что представление данных в виде столбчатых диаграмм (рисунок 1.) затрудняет получение точных количественных оценок. Несмотря на это, анализ материалов исследований позволяют констатировать, что величина показателя очень сильно варьирует по субъектам РФ. Так, в Магаданской области и Ямало-Ненецком АО она равна 106,0 и 111,7 тыс. руб. на ученика, а в Свердловской, Брянской и Новгородской областях $-13,4,10,9$ и 9,3 тыс. руб. соответственно, т.е. имеет место расхождение на порядок. Также НИУ ВШЭ обоснованно критикует региональные подходы к формированию душевых нормативов, из-за чего их номинальная величина оказывается существенно ниже реальных потребностей. Так, например, для Амурской области утвержденное на уровне региона значение показателя составило 11,1 тыс. руб., в то время как «справедливый» (по оценке НИУ ВШЭ) норматив, реально отражающий все затраты на организацию учебного процесса, должен иметь величину 45,2 тыс. руб.; соответствующее соотношение для Республики Татарстан $-35,0$ и 53,2 тыс. руб. и т.д. Даже в таком благополучном регионе, как Москва, значения показателей $-63,1$ и 111,5 тыс. руб., т.е. номинальное значение норматива составляет менее $60 \%$ от реально необходимой величины. Напротив, в ряде регионов душевой норматив завышается: в Республике Коми - 87,6 тыс. руб. при «справедливом» значении 68,6 тыс. руб., в Тюменской области $-60,5$ 


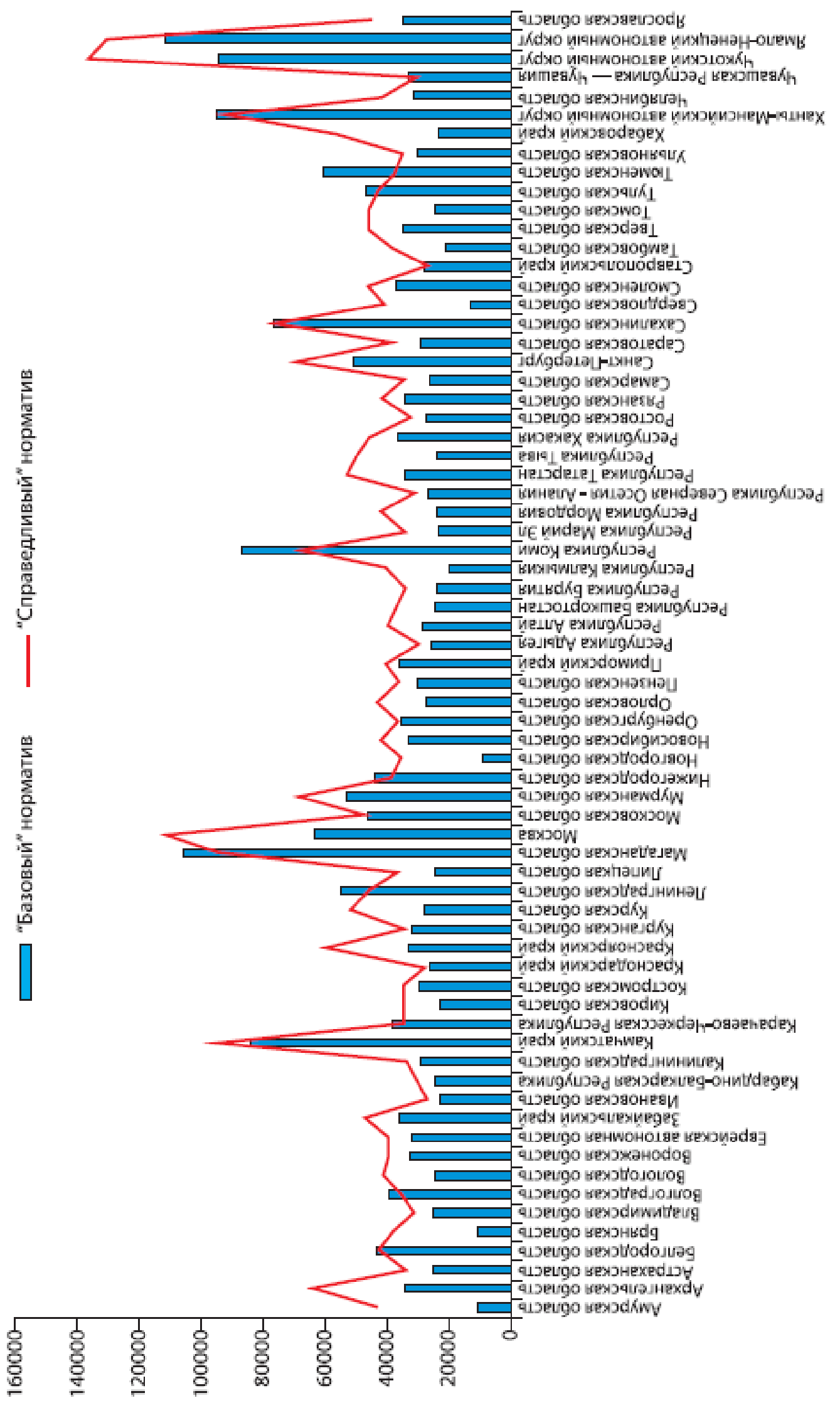


и 37,4 тыс. руб. соответственно. Для централизованного планирования объемов финансирования системы общего образования необходимо произвести расчет общероссийского норматива как средневзвешенного значения по всем регионам, с учетом численности учащихся в них. Однако в существующем варианте формирования душевой норматив финансирования не может быть признан эффективным инструментом.

Ниже приводится разработанная авторами упрощенная методика определения душевого норматива финансирования, базирующаяся на следующем расчетном алгоритме:

$$
\Phi_{1}=\text { Зпед. * Nпед. = Зсредн. * Nпед. }
$$

где: $\Phi_{1}-$ месячный фонд зарплаты педагогических работников в системе общего образования (без учета начислений на зарплату);

Зпед. и Зсредн.- зарплата педагогических работников и средняя зарплата по экономике в целом;

Nпед.- численность педагогических работников в системе общего образования.

При расчете по (1) предполагается, что зарплата педагогических работников соответствует уровню средней по экономике в соответствии с требованиями инаугурационных указов Президента РФ 2012 г. [4], [5].

$$
\begin{aligned}
& \Phi_{2}=\Phi_{1} *(1+0,856 * 0,392 / 0,608)= \\
& 1,552 * \Phi_{1}=1,552 * \text { Зсредн. } * \text { Nпед. }
\end{aligned}
$$

где: $\Phi_{2}$ - месячный фонд зарплат работников всех категорий в системе общего образования без учета начислений на зарплату и внешних управленческих расходов.

Расчет по (2) производится с учетом того, что педагогические работники составляют 0,608 от общей численности занятых в общем образовании, а их зарплата в 1,168 раза выше, чем у работников прочих категорий - см. данные исследований МгУТУ им. К.Г. Разумовского [9].

$$
\begin{aligned}
& \Phi_{3}=\Phi_{2} / 0,558=1,792 * \Phi_{2}= \\
& 2,781 * \text { Зсредн. * Nпед. }
\end{aligned}
$$

где: Ф3- величина расходов общеобразовательных учреждений без учета внешних управленческих расходов.

Расчет по (3)производится с учетом того, что выплаты персоналу составляют $55,8 \%$ расходов общеобразовательных учреждений - см. данные исследований НИУ ВШЭ [10].

$$
\begin{aligned}
& \Phi_{4}=1,09 * \Phi_{3}=3,031 * \text { Зсредн. }{ }^{*} \text { Nпед. } \\
& \Phi_{4 \text { год. }}=12 * \Phi_{4}=36,375 * \text { Зсредн. }{ }^{*} \text { Nпед }
\end{aligned}
$$

где Ф4 и Ф4год.- полный месячный и годовой объемы финансирования системы общего образования с учетом внешних управленческих расходов.

Расчет по (4) производится с учетом того, что внешние управленческие расходы (на содержание органов управления общим образованием) составляют 9\% от суммарных расходов СОШ- см. данные источника [10].

$$
\begin{aligned}
& \text { Нподуш. = Ф4год } / \text { Nуч. }= \\
& \text { 36,375 * Зсредн. * Nпед. / Nуч. }
\end{aligned}
$$

где: Нподуш.- норматив подушевого финансирования по системе общего образования в целом;

Nуч.- численность учащихся в системе общего образования.

Оценим точность предлагаемой методики на основании имеющихся статистических данных [15]. По состоянию на 2015 г. фактические значения основных показателей, фигурирующих в расчетах, составляли:

$$
\begin{aligned}
& \text { Зсредн. = 30,694 тыс. руб.; } \\
& \text { Кпед. = 1286,452 тыс. чел.; } \\
& \text { Nуч. = 14596, } 300 \text { тыс. чел. }
\end{aligned}
$$

Расчетное значение подушевого норматива финансирования в соответствии с (6)будет равно:

Нподуш.2015 = 36,375 * 30694 * 1286452 /

$14596300=98,40$ руб.

При этом соответствующий расчетный объем выделяемого финансирования составит:

$\Phi_{2015}=$ уч. ${ }^{*}$ Нподуш. $2015=14596300 * 98,40=$ 1436.3 млрд.руб.

Фактические значения показателей в 2015 г.95,9 тыс. руб. и 1405,9 млрд. руб. согласно данным статистического сборника «Индикаторы образования» [11], что составляет 97,9\% и 97,4\% от расчетных значений. Полученный результат свидетельствует о достаточно высокой точности предлагаемой расчетной процедуры, а также о 
необоснованности широко распространенного утверждения о серьезном недофинансировании общего образования.

Аналогичные расчеты для 2016 г. могут быть проделаны лишь на основании прогнозных значений показателей, поскольку соответствующие фактические данные в Единой информационной системе обеспечения деятельности МОН РФ [12] пока не размещены. Результаты расчетов показывают, что потребность системы общего образования в финансировании составит 1477,2 млрд. руб. при выделенном на эти цели объеме средств 1540,0 млрд. руб., что соответствует удовлетворению фактической потребности на $104,2 \%$.

Таким образом, справедливо предположение, что проблема финансирования общеобразовательных учреждений заключается не в нехватке средств, а в отсутствии механизма доведения их до первичного звена, т.е. до СОШ. На основании полученных результатов может быть предложен следующий алгоритм процесса финансирования системы общего образования:

1. По каждому субъекту РФ на основании (6) определяется подушевой норматив финансирования и соответствующий потребный объем годового финансирования. Если средства имеются в необходимом объеме, следует переход к следующему пункту, если нет, ставится вопрос о выделении субсидии из средств федерального бюджета.

2. Из выделенных средств выделяется доля в размере 91,7\% для удовлетворения потребностей общеобразовательных учреждений, остаток представляет собой управленческие расходы всех звеньев на региональном уровне за исключением первичного - согласно (4). Теоретически объем выделенных средств обеспечивает потребности образовательных учреждений на $104,2 \%$ (см. данные прогнозных расчетов для 2016 г.), соответственно в школы направляется 96\% объема, что гарантирует уровень зарплаты педагогических работников как минимум равной средней по экономике региона.

3. Остаток средств (4\%) распределяется между муниципальными образованиями субъекта РФ по результатам открытой конкурсной процедуры, основанной на оценке их достижений в образовательной деятельности с помощью балльно-рейтингового подхода, подробно описанного в исследованиях МГУТУ им. К.Г. Разумовского [13]. Аналогичным образом средства распределяются между образовательными учреждениями внутри каждого муниципального образования, но, естественно, критерии оценки достижений при этом могут отличаться от использовавшихся на региональном уровне. Таким образом, наиболее успешные СОШ получают бонус в виде дополнительного финансирования - так, если $50 \%$ школ будут отмечены за достигнутые успехи, объем дополнительного финансирования для них составит 8\% от номинального уровня.

Поясним теоретические основы и механизм практического применения, упоминавшегося выше, балльно-рейтингового подхода к оценке достижений в образовательной деятельности на региональном уровне, поскольку наибольшая доля финансовых средств (почти 80\%) поступает в СОШ из региональных бюджетов. Данный подход базируется на известном принципе управления по результатам [6] и предполагает стимулирование наиболее важных на текущий момент направлений активности управляемой системы. В соответствии с этим необходимо определить, какие аспекты образовательной деятельности являются наиболее приоритетными для конкретного региона, при этом их число не должно быть чрезмерно велико - как правило, не более 4-5. Но независимо от региональной специфики в число приоритетов в обязательном порядке должны включаться:

a) успехи учащихся, достигнутые на различных уровнях (международном, общероссийском, региональном) как конечная цель образовательного процесса;

б) профессиональные показатели состояния учительского корпуса как важнейшего фактора обеспечения качества учебного процесса;

в) показатели здоровья учеников, поскольку никакая цель, пусть даже самая высокая, не может служить оправданием потери здоровья подрастающего поколения за годы обучения в школе.

Дополнительно по выбору региональных властей к списку могут быть добавлены разнообразные показатели - информатизация учебного процесса, охват учеников мероприятиями продленного дня, организация школьного питания и пр., пока же ограничимся тремя важнейшими. Каждому приоритетному показателю присваивается индивидуальный коэффициент весомости, в соответствии с важностью для региональной образовательной системы. Остаток 
средств (4\%) распределяется на доли по числу приоритетных показателей в соответствии с формулой:

$$
\mathbf{S i}=\mathbf{S} * \frac{R i * N i}{\sum_{i=1}^{3} R i * N i}
$$

где: $\mathrm{S}$ и $\mathrm{Si}$ - размеры общего объема распределяемого остатка средств и его долей за достижения в $i$-м аспекте образовательной деятельности.

$R i$ - коэффициент весомости, утверждаемый для $i$-го аспекта на региональном уровне;

$\mathrm{Ni}$ - число муниципальных образований, претендующих на получение дополнительных средств за высокие достигнутые результаты деятельности по приоритетным направлениям.

Размер дополнительных денежных средств, выделяемых конкретным муниципальным образованиям, зависит от уровня активности (чаще всего - не более трех уровней), показанных ими в приоритетных направлениях образовательной деятельности и может быть определен по формуле:

$$
\mathrm{C}_{i j}=\mathrm{S} i * \frac{\mathrm{K} i j}{\sum_{j=1}^{3} \mathrm{~N} i j * \mathrm{~K} i j}
$$

где: $\mathrm{C}_{i j^{-}}$размер денежных средств, выделяемых муниципальному образованию, проявившему $j$-й уровень активности $(j=1 \div 3) i$-м виде деятельности $(i=1 \div 3)$;

$\mathrm{N}_{i j}$ - количество муниципальных образований, проявивших в $i$-м виде деятельности активность $j$-го уровня;

$\mathrm{K}_{i j}$ - балльная оценка $j$-го уровня активности муниципального образования в $i$-й области деятельности, устанавливаемая на региональном уровне.

Один из возможных вариантов оценки активности по различным приоритетным направлениям образовательной деятельности представлен в табл. 1. Без сомнения, важнейшим показателем эффективности учебного процесса является доля выпускников СОШ, поступивших в ведущие вузы РФ. Поскольку прием в них осуществляется по результатам ЕГЭ, именно этот показатель мог бы использоваться в качестве ключевого при оценке успехов учащихся. Однако с учетом того, что с 2016 г. результаты ЕГЭ по регионам РФ в открытом доступе не публикуются, можно оценивать успешность учеников по результатам участия региональных школ в международном исследовании PISA, а также по ряду других параметров. В качестве важнейшего показателя профессионального статуса педагогического корпуса принято количество молодых учителей, задача удержания которых в профессии является приоритетной для отечественного образования. Очевидно, ранжирование уровней активности может осуществляться и отличным от принятого в таблице 1 способом (например, 3 -й уровень может начинаться не со 105\%, а с $110 \%$ от среднего значения показателя по региону и т.д.).

Внутри муниципальных образований производится распределение денежных средств между отдельными образовательными учреждениями по формулам, аналогичным (7)-(8), однако критерии проявления активности СОШ по различным приоритетным направлениям деятельности могут формулироваться несколько иначе, чем для муниципальных образований в целом.

Приведем пример использования предлагаемого подхода. Пусть в некотором субъекте РФ, насчитывающем 267 муниципальных образований, установлены следующие коэффициенты весомости для приоритетных направлений деятельности системы общего образования: 0,5 - успехи учеников; 0,3 - показатели профессионального состояния учительского корпуса; 0,2 - показатели здоровья учеников. Показали хорошие результаты и претендуют на выделение дополнительных средств по первому направлению деятельности 111 муниципальных образований, по второму - 129 и по третьему 145. В соответствии с (7) доли $4 \%$-ного остатка S средств по видам деятельности составят:

$$
\begin{aligned}
& \mathrm{S}_{1}=\mathrm{S} * \frac{0,5 * 111}{0,5 * 111+0,3 * 129+0,2 * 145}=\mathrm{S} * \frac{55,5}{123,2}=\mathrm{S} * 0,450 \\
& \mathrm{~S}_{2}=\mathrm{S} * \frac{0,3 * 129}{0,5 * 111+0,3 * 129+0,2 * 145}=\mathrm{S} * \frac{38,7}{123,2}=\mathrm{S} * 0,314 \\
& \mathrm{~S}_{3}=\mathrm{S} * \frac{0,2 * 145}{0,5 * 111+0,3 * 129+0,2 * 145}=\mathrm{S} * \frac{29,0}{123,2}=\mathrm{S} * 0,236
\end{aligned}
$$

Можно видеть, что условие нормировки соблюдается $\left(\mathrm{S}_{1}+\mathrm{S}_{2}+\mathrm{S}_{3}=\mathrm{S}\right)$, т.е. размеры долей вычислены верно.

Далее предположим, что уровням активности присвоены следующие балльные оценки 20 за первый (низший), 50 - за второй (средний) и 100 - за третий (наивысший), при этом по первому направлению деятельности третий уровень продемонстрировали 65 муниципальных образований, второй -37 и первый - 9. В 


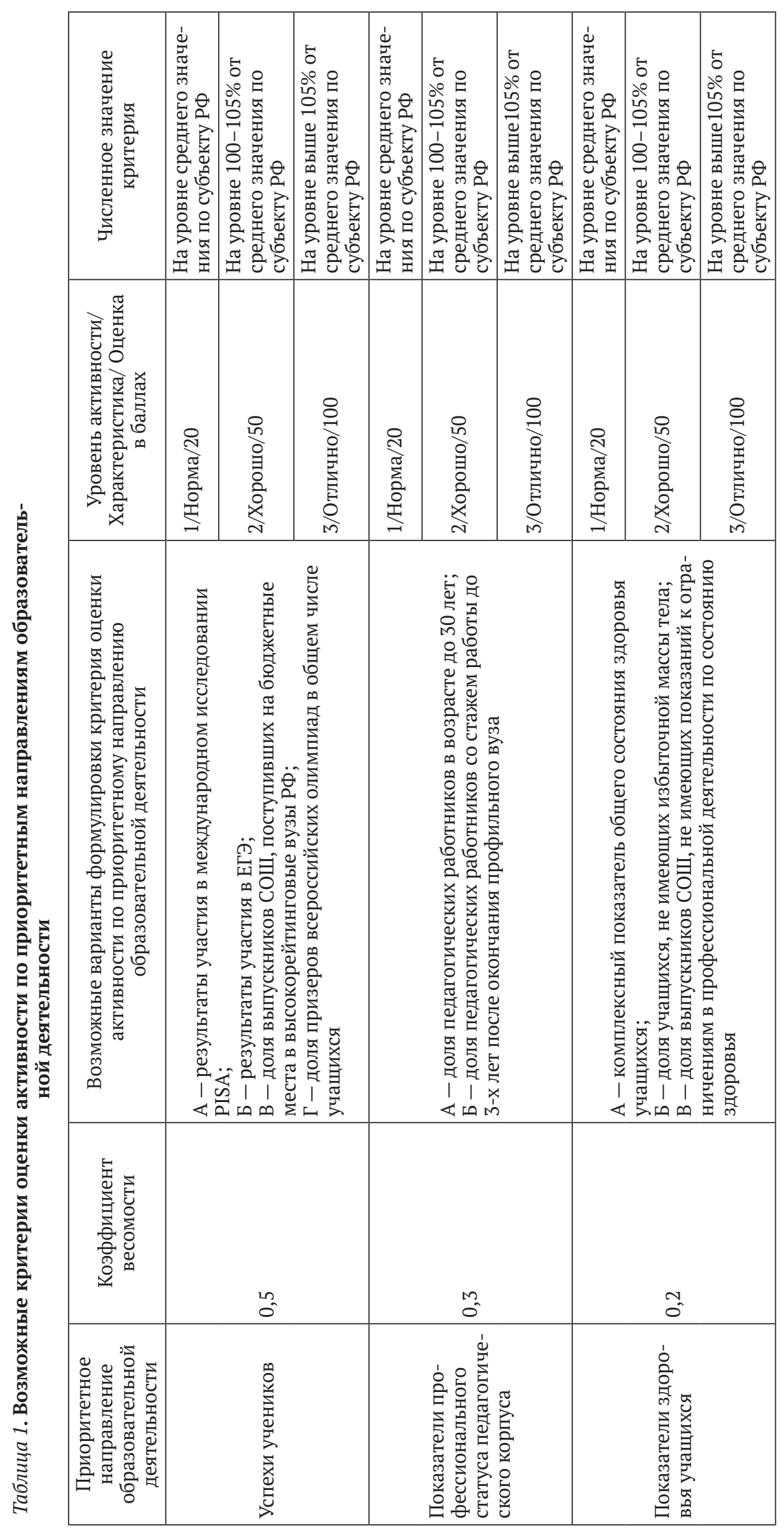


соответствии с (8) будем иметь размеры дополнительных объемов финансирования, выделяемых каждому муниципальному образованию за проявленные уровни активности по первому приоритетному направлению:

$$
\begin{aligned}
& \mathrm{C}_{11}=\mathrm{S}_{1} * \frac{20}{20 * 65+50 * 37+100 * 9}=\mathrm{S}_{1} * \frac{20}{4050}=\mathrm{S}_{1} * 0,00494=\mathrm{S}^{*} 0,00222 \\
& \mathrm{C}_{12}=\mathrm{S}_{1} * \frac{50}{20 * 65+50 * 37+100 * 9}=\mathrm{S}_{1} * \frac{50}{4050}=\mathrm{S}_{1} * 0,01235=\mathrm{S} * 0,00556 \\
& \mathrm{C}_{13}=\mathrm{S}_{1} * \frac{100}{20 * 65+50 * 37+100 * 9}=\mathrm{S}_{1} * \frac{100}{4050}=\mathrm{S}_{1} * 0,02469=\mathrm{S} * 0,01111
\end{aligned}
$$

Проверка выполнения условия нормировки: $\mathrm{C}_{11}{ }^{*} \mathrm{~N}_{11}+\mathrm{C}_{12}{ }^{*} \mathrm{~N}_{12}+\mathrm{C}_{13} * \mathrm{~N}_{13}=\mathrm{S}_{1} * 0,00494 * 65+\mathrm{S}_{1}$ * $0,01235 * 37+\mathrm{S}_{1} * 0,02469 * 9=\mathrm{S}_{1} * 1,00000$

Аналогичным образом могут быть вычислены объемы дополнительного финансирования $\mathrm{C}_{2 j}$ и $\mathrm{C}_{3 j}$ по второму и третьему направлениям образовательной деятельности. Эффективность предлагаемой методики апробирована при начислении повышенной академической стипендии студентам за успехи, достигнутые в учебной, научной, общественной, спортивной и пр. деятельности [13]. Также она может быть применена при формировании стимулирующей части зарплаты учителей, более детальное ее рассмотрение не представляется возможным в связи с ограниченным объемом настоящей работы. Однако можно утверждать, что при фактических объемах финансирования системы общего образования применение данной методики позволяет средней зарплате педагогических работников гарантированно достичь уровня 104\% от средней зарплаты по экономике в целом. В свою очередь, это обеспечивает вхождение школьных учителей в состав российского среднего класса, что существенно способствует поддержанию социальной стабильности [14].

\section{Библиографический список}

1. Батова Б.З., Асланова Л.О., Аликаева М.В., Губачиков А.М. Проблемы финансирования образования в России // Фундаментальные исследования.2016. № 5 (часть 3). С. 546-550.

2. Иванова В.Н., Оздарбиев Р.Г., Таточенко И.М. Анализ объемов финансирования отечественного общего образования в свете выполнения требований инаугурационных указов Президента Российской Федерации // Экономические науки. 2017. № 157. С. 21-25.

3. Самсонова О.В. Проблемы управления образованием. Инвестиции в образование // Государственное управление. Электронный вестник. Выпуск № 16. Сентябрь 2008 г. [Электронный ресурс]. Режим доступа: http:// e-journal.spa.msu.ru/

4. Указ Президента РФ от 07.05.2012 № 599 «О мерах по реализации государственной политики в области образования и науки»

5. Указ Президента РФ от 07.05.2012 г. N597 «О мероприятиях по реализации государственной социальной политики»

6. Третьяков П.И. Основы системы управления образования по результатам деятельности организаций // Педагогическое образование и наука. 2017. № 1. С. 44-49.

7. Абанкина И.В., Алашкевич М. Ю., Винарик В.А. и др. Анализ нормативного подушевого финансирования общего образования в субъектах Российской Федерации. Москва: НИУ ВШЭ. 2016. 64 с.

8. Абанкина И.В., Алашкевич М.Ю., Баринов С.Л.. и др. Справедливость нормативного подущевого финансирования образования в России. Млсква: НИУ ВШЭ. 2017. 120 с.

9. Иванова В.Н., Оздарбиев Р.Г., Таточенко А.Л. Зарплата педагогических работников в сфере общего образования: оценка сроков достижения паритета со средней зарплатой в экономике на основе анализа динамики временных рядов показателей // Экономические науки. 2017. № 152. С. 25-30.

10. Структура расходов общеобразовательных учреждений. НИУ ВШЭ - Мониторинг экономики образования [Электронный ресурс]. Режим доступа: https://memo.hse.ru/ ind_w08_3_08.

11. Бондаренко Н.В., Гохберг Л. М., Забатурина И. Ю. и др. Индикаторы образования. Москва: НИУ ВШЭ. 2017.320 c.

12. Единая информационная система обеспечения деятельности МОН РФ [Электронный ресурс]. Режим доступа: http://eis.mon.gov.ru/education/

13. Иванова В.Н., Пахомов А.А., Стерликов Ф.Ф., Таточенко А.Л. О разработке методики расчета размера повышенной государственной академической стипендии студентам российских вузов // Вопросы экономики и права. 2013. № 63. С. 110-114. 
14. Иванова В.Н., Оздарбиев Р.Г., Таточенко А.Л. Российские учителя: перспективы вхождения в средний класс при условии выполнения требований инаугурационных президентских указов // Экономические науки. 2017. № 151. С. 34-38.

15. Официальный сайт Федеральной службы государственной статистики [Электронный ресурс]. Режим доступа: https://gks.ru

Поступила в редакцию 09.09.2018 